\title{
Roxithromycin attenuates inflammation via modulation of RAGE-influenced calprotectin expression in a neutrophilic asthma model
}

\author{
Xiaofei Gu ${ }^{1,2,3}$, Danni Shu ${ }^{3}$, Songmin Ying ${ }^{4}$, Yuanrong Dai ${ }^{3}$, Qi Zhang ${ }^{3}$, Xinmiao Chen ${ }^{3}$, Huijun Chen ${ }^{5}$, \\ Wei Dai ${ }^{1}$
}

${ }^{1}$ Department of Neurology Rehabilitation, The Second Affiliated Hospital of Wenzhou Medical University, Wenzhou, China; ${ }^{2}$ Department of Respiratory and Critical Care Medicine, Yuhang First People's Hospital, Hangzhou, China; ${ }^{3}$ Department of Respiratory Medicine, The Second Affiliated Hospital and Yuying Children's Hospital of Wenzhou Medical University, Wenzhou, China; ${ }^{4}$ Department of Respiratory and Critical Care Medicine, The Second Affiliated Hospital Department of Pharmacology, Zhejiang University School of Medicine, Hangzhou, China; ${ }^{5}$ Department of Respiratory Medicine, Jinhua Municipal Central Hospital, Jinhua, China

Contributions: (I) Conception and design: X Gu, H Chen; (II) Administrative support: W Dai, H Chen, S Ying; (III) Provision of study materials or patients: Y Dai, H Chen; (IV) Collection and assembly of data: X Gu; (V) Data analysis and interpretation: X Gu; (VI) Manuscript writing: All authors; (VII) Final approval of manuscript: All authors.

Correspondence to: Professor Wei Dai. Department of Neurology Rehabilitation, the Second Affiliated Hospital of Wenzhou Medical University, 109 Xueyuan Road, Wenzhou 325027, China. Email: daiweijh@sina.com; Professor Huijun Chen. Department of Respiratory Medicine, Jinhua Municipal Central Hospital, 351 Mingyue Street, Jinhua 321000, China. Email: chj0577@163.com.

Background: Roxithromycin (RXM), a macrolide antibiotic, exhibits anti-asthmatic effects, but its specific mechanism of action remains elusive. We evaluated the effects of RXM on airway inflammation, the expression of calprotectin, and the activity of the receptor of advanced glycation end products (RAGE) to determine whether RXM alleviates inflammation by regulating RAGE activation, and thereby calprotectin expression, in neutrophilic asthma.

Methods: Male Brown Norway rats were sensitized with ovalbumin (OVA) and Freund's complete adjuvant (FCA) mixture, followed by OVA challenge to induce neutrophilic asthma. RXM (30 mg/kg) or FPS-ZM1 (RAGE inhibitor, $1.5 \mathrm{mg} / \mathrm{kg}$ ) was administered $30 \mathrm{~min}$ prior to each challenge. The infiltration of airway inflammatory cells and cytokines, as well as the expression of calprotectin and RAGE, was assessed.

Results: The expression of airway inflammatory cells and cytokines was found to be significantly elevated in OVA + FCA-induced rats. Increased expression of both calprotectin and RAGE was also detected in OVA + FCA-induced asthma [bronchoalveolar lavage fluid (BALF) calprotectin: $15.07 \pm 1.79$ vs. $3.86 \pm 0.69 \mathrm{ng} / \mathrm{mL}$; serum calprotectin: $20.47 \pm 1.64$ vs. $9.29 \pm 1.31 \mathrm{ng} / \mathrm{mL}$; lung tissue homogenates calprotectin: $28.82 \pm 1.01$ vs. $12.02 \pm 1.38 \mathrm{ng} / \mathrm{mg}$; BALF RAGE: $762.93 \pm 36.47$ vs. $294.25 \pm 45.92 \mathrm{ng} / \mathrm{mL}$; serum RAGE: $906.43 \pm 58.95$ vs. $505.60 \pm 30.16 \mathrm{ng} / \mathrm{mL}$; lung tissue homogenates RAGE: $1,585.24 \pm 177.59$ vs. $461.53 \pm 63.40 \mathrm{ng} / \mathrm{mg}$; all $\mathrm{P}<0.001]$. However, all of these changes were interrupted by RXM and FPS-ZM1.

Conclusions: RXM exerted similar effects as the RAGE inhibitor FPS-ZM1 in terms of reducing airway inflammation and downregulating the expression of calprotectin and RAGE in a neutrophilic asthma model. Our findings provide novel insights into the mechanisms underlying the effect of RXM pretreatment on neutrophilic asthma. Furthermore, FPS-ZM1 may be useful as an intervention specific to the neutrophilic asthma phenotype.

Keywords: Calprotectin; receptor of advanced glycation end products (RAGE); roxithromycin (RXM); asthma; airway inflammation

Submitted Jan 12, 2021. Accepted for publication Mar 20, 2021.

doi: $10.21037 /$ atm-21-859

View this article at: http://dx.doi.org/10.21037/atm-21-859 


\section{Introduction}

Asthma is a heterogeneous disease with various phenotypes, and is mainly characterized by airway inflammation and airway hyperresponsiveness (1). Increasing evidence indicates that airway neutrophil infiltration in asthma is associated with disease severity and acute asthma exacerbation (2). Therefore, having safe and effective treatments for neutrophilic asthma is crucial.

MRP8 and MRP14, members of the S100 protein family, exist as the protein heterodimer calprotectin (also called S100A8/A9). Calprotectin is predominantly expressed by activated neutrophils, and comprises $>30 \%$ of neutrophil cytoplasmic proteins (3). Recently, it was identified as an important damage-associated molecular pattern (DAMP) via the receptor of advanced glycation end products (RAGE) and Toll-like receptor 4 (TLR4) (4,5). Emerging evidence suggests that calprotectin is a useful biomarker of inflammatory processes, including rheumatoid arthritis, juvenile idiopathic arthritis, and inflammatory bowel disease (6). The recent study has shown that calprotectin levels in patients with asthma correlated negatively with forced expiratory volume in one second/forced vital capacity, body mass index, and positively with smoke amount and blood neutrophil percentage (7). In addition, calprotectin has a pivotal role in inflammation by inducing the secretion of inflammatory cytokines $(8,9)$. Owing to its critical involvement in inflammatory reactions, calprotectin has received significant attention in studies of asthma $(10,11)$.

RAGE, a multi-ligand receptor belonging to the immunoglobulin receptor superfamily, is an important transmembrane protein (12). There is a growing body of evidence implicating RAGE, via the binding of its ligands, including calprotectin, as a major driving mechanism in the pathogenesis of inflammatory states (13-15). Furthermore, one study showed that RAGE and its ligands may be potential hallmarks for inflammatory disorder progression and severity (16). Nevertheless, little has been revealed about RAGE's role in asthma to date.

It has been shown that macrolides appear to be beneficial in the prevention of myocardial remodeling via matrix metalloproteinase (MMP) and nitric oxide (NO) regulation, which indicates that macrolides may be alternative therapies for suppressing inflammatory remodeling $(17,18)$. Roxithromycin (RXM), a broad-spectrum macrolide antibiotic, enhances phagocytosis and the bactericidal activities of neutrophils (19). Studies demonstrated that RXM ameliorates colitis by suppressing oxidative stress and downregulating NF- $\mathrm{KB}-$ mediated proinflammatory signaling $(20,21)$. Furthermore, it has become increasingly evident that RXM has efficacy in reducing the risk of asthma exacerbations $(22,23)$; however, the mechanisms underlying this effect are not yet fully understood.

In this study, we established a neutrophilic asthma model to investigate the effects of RXM and its underlying mechanisms. To this end, we hypothesized that RXM may alleviate airway inflammation via inhibition of RAGE, which modulates the expression of calprotectin.

We present the following article in accordance with the ARRIVE reporting checklist (available at http://dx.doi. org/10.21037/atm-21-859).

\section{Methods}

\section{Animals and grouping}

Male Brown Norway rats, aged 6-8 weeks and weighing 150-180 g, were obtained from the Beijing Vital River Laboratory Animal Center (Beijing, China) and allowed to acclimate to their environment for 7 days. The rats were kept in a pathogen-free environment at $25{ }^{\circ} \mathrm{C}$ with a 12-h light/dark cycle, and were allowed access to food and water ad libitum. Experiments were performed under a project license (protocol wydw2019-019) granted by the Animal Care and Protection Committee of Wenzhou Medical University, in compliance with the Animal Care and Protection Committee of Wenzhou Medical University guidelines for the care and use of animals. The rats were randomly assigned to four groups (each comprising six rats): control, asthma, asthma + FPS-ZM1, asthma + RXM.

\section{Neutrophilic asthma model and treatments}

Our neutrophilic asthma model was established according to the improved method of Dejager et al. (24). Briefly, the rats were sensitized with an intraperitoneal (i.p.) injection of $0.5 \mathrm{mg}$ ovalbumin (OVA, Sigma-Aldrich, USA) emulsified in $0.5 \mathrm{~mL}$ Freund's complete adjuvant (FCA, SigmaAldrich, USA) in $0.5 \mathrm{~mL}$ normal saline (NS) on days 1 and 8. From days $15-19$, the sensitized rats were challenged with 1\% OVA aerosol for 30 min once daily. Rats in the asthma + RXM group had intragastric (i.g.) administration of RXM (MedChemExpress, USA; $30 \mathrm{mg} / \mathrm{kg}$ ), and rats in the asthma + FPS-ZM1 group had i.g. administration of FPSZM1 (SelleckChem, USA; $1.5 \mathrm{mg} / \mathrm{kg}$ ) $30 \mathrm{~min}$ before the challenge. Rats in the control group were sham-sensitized and challenged with NS (Figure 1A). 
A

OVA+FCA sensitization

$1 \%$ OVA challenge

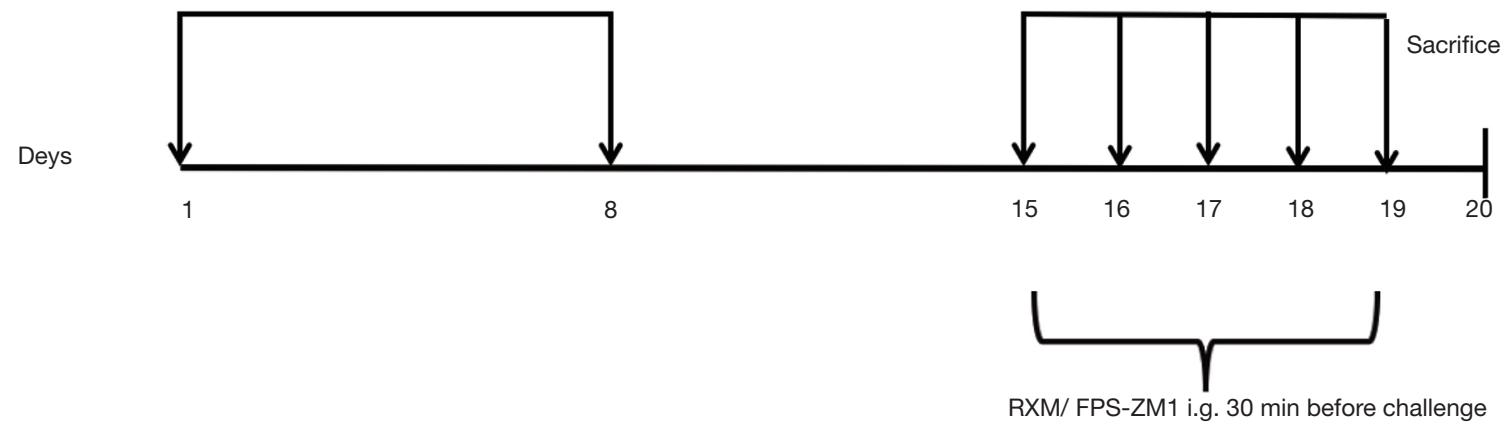

B

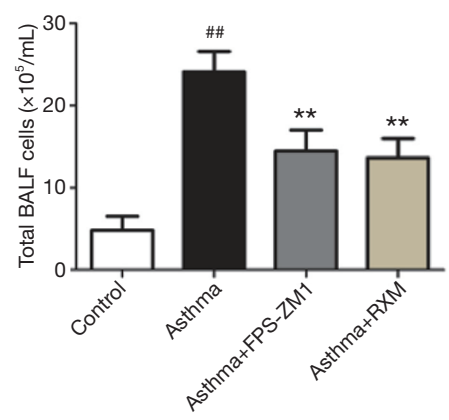

C

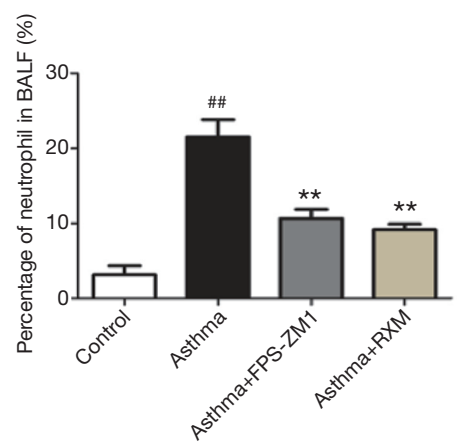

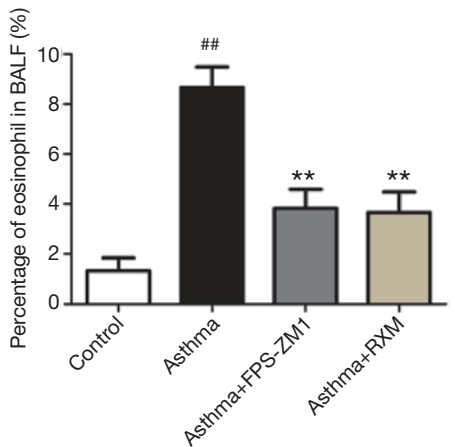

Figure 1 Effects of roxithromycin (RXM) on bronchoalveolar lavage fluid (BALF) cells of ovalbumin (OVA)+ Freund's complete adjuvant (FCA)-induced rats. (A) Experimental protocols for the neutrophilic asthma model and treatments. Total cells (B), percentage of neutrophil (C), and percentage of eosinophil (D) in BALF. Data are expressed as mean \pm standard deviation (SD) ( $\mathrm{n}=4-6$ per group). ${ }^{\#}, \mathrm{P}<0.01$ compared to the control group; ${ }^{* *}, \mathrm{P}<0.01$ compared to the asthma group.

\section{Collection of serum and bronchoalveolar lavage fluid (BALF)}

The rats were anesthetized and humanely killed $24 \mathrm{~h}$ after the last challenge. Blood samples were collected from the abdominal aorta and the supernatants were centrifuged at $1,006 \mathrm{~g}$ for $15 \mathrm{~min}$ and stored at $-80^{\circ} \mathrm{C}$. The rats' left lungs were washed with saline solution via a tracheal cannula, and the fluid collected was centrifuged at $112 \mathrm{~g}$ for $15 \mathrm{~min}$ at $4{ }^{\circ} \mathrm{C}$. The supernatants were kept as BALF and stored at $-80{ }^{\circ} \mathrm{C}$. The cell pellet was resuspended in saline solution using a hemocytometer (Bio-Rad, USA) to count the total number of cells. Wright's staining was performed to obtain differential cell counts.

\section{Histopathological analysis}

The rats' right lungs were fixed in $4 \%$ paraformaldehyde and stained with hematoxylin and eosin (H\&E) for light microscopy (Leica, Germany). The inflammation score was evaluated by a sample-blinded pathologist using the H\&Estained sections (25).

\section{Enzyme-linked immunosorbent assay}

The concentrations of calprotectin, RAGE, interleukin (IL)17 , and IL-6 in BALF and serum, and the concentrations of calprotectin and RAGE in lung tissues, were quantified using enzyme-linked immunosorbent assay (ELISA) kits (Absin, China) according to the manufacturer's protocols.

\section{Western blotting analysis}

The isolated lungs were flash-frozen in liquid nitrogen, then homogenized and sonicated in ice-cold RIPA lysis buffer (Beyotime, China) containing protease and 
phosphatase inhibitor (Applygen, China) to obtain protein extracts. A total of $50 \mu \mathrm{g}$ of protein was loaded onto $10 \%$ or $12 \%$ sodium dodecyl sulfate (SDS)-polyacrylamide gels for electrophoresis (SDS-PAGE) and transferred onto polyvinylidene difluoride (PVDF) membranes (Millipore, USA). Membranes were blocked with Tris-buffered saline containing $5 \%$ non-fat dried milk for $2 \mathrm{~h}$ prior to incubation with primary antibodies against RAGE (Santa Cruz, USA) and GAPDH (CST, USA), respectively, overnight at $4{ }^{\circ} \mathrm{C}$. The membranes were incubated with HRP-conjugated anti-mouse or anti-rabbit secondary antibodies (Biosharp, China) for $1.5 \mathrm{~h}$ at room temperature. After treatment with enhanced chemiluminescent reagents (Pierce, USA), the target protein was quantitatively analyzed using Image Lab software (Bio-Rad, USA) (target protein gray value/ GAPDH gray value).

\section{Statistical analysis}

The data are expressed as mean \pm standard deviation (SD). Comparisons among groups were performed using one-way analysis of variance followed by Tukey's (equal variances assumed) or Dunnett's (equal variances not assumed) post-hoc multiple comparisons. Correlation analysis was conducted using Pearson's correlation coefficient. SPSS 21.0 software (SPSS, USA) was used for statistical analyses, and $\mathrm{P}<0.05$ was considered statistically significant.

\section{Results}

\section{Effect of RXM on airway inflammatory cells in BALF}

Our results revealed a notable increase in the total number of inflammatory cells in OVA + FCA-induced rats relative to controls $\left[(24.12 \pm 2.49)\right.$ vs. $(4.82 \pm 1.68) \times 10^{5} / \mathrm{mL}, \mathrm{P}<0.001$, Figure $1 B]$, especially in the percentage of neutrophils $(21.50 \% \pm 2.35 \%$ vs. $3.17 \% \pm 1.17 \%, \mathrm{P}<0.001$, Figure $1 C)$. The percentage of eosinophils was also increased in OVA + FCA-induced rats relative to controls $(8.67 \% \pm 0.82 \% v s$. $1.33 \% \pm 0.52 \%, \mathrm{P}<0.001$, Figure $1 D)$. Treatment with RXM significantly reduced these effects compared with the asthma group $\left[(13.63 \pm 2.36) v s .(24.12 \pm 2.49) \times 10^{5} / \mathrm{mL} ; 9.17 \% \pm 0.75 \%\right.$ vs. $21.50 \% \pm 2.35 \% ; 3.67 \% \pm 0.82 \%$ vs. $8.67 \% \pm 0.82 \%$; all $\mathrm{P}<0.001$, Figure 1].

\section{Effect of RXM on infiltration of airway inflammatory cells}

Relative to the controls, OVA + FCA-induced rats developed evidently narrowed airways, increased mucosal wrinkles, and extensive inflammatory cell infiltration and aggregation in the bronchi, perivascular, and alveolar spaces (Figure 2A). The RXM treatment suppressed these histopathological responses, demonstrating more antiinflammatory activity relative to the asthma group (Figure 2).

\section{Effect of RXM on inflammatory cytokines in BALF and serum}

The concentrations of IL-17 and IL- 6 in the BALF $(136.31 \pm 6.18$ vs. $32.65 \pm 9.17 \mathrm{ng} / \mathrm{mL} ; 69.60 \pm 6.02$ vs. $10.62 \pm 3.83 \mathrm{ng} / \mathrm{mL}$; all $\mathrm{P}<0.001)$ and serum $(185.76 \pm 18.82$ vs. $89.15 \pm 15.24 \mathrm{ng} / \mathrm{mL} ; 99.16 \pm 9.60$ vs. $46.65 \pm 5.59 \mathrm{ng} / \mathrm{mL}$; all $\mathrm{P}<0.001)$ were markedly elevated in the asthma group compared with controls (Figure $3 A, B$ ). Of note, all of these elevated expression levels were reduced by RXM compared with the asthma group $(108.12 \pm 8.28 v s .136 .31 \pm 6.18 \mathrm{ng} / \mathrm{mL}$, $\mathrm{P}=0.002 ; 39.07 \pm 6.95$ vs. $69.60 \pm 6.02 \mathrm{ng} / \mathrm{mL}, \mathrm{P}<0.001$; $138.42 \pm 15.13$ vs. $185.76 \pm 18.82 \mathrm{ng} / \mathrm{mL}, \mathrm{P}=0.007 ; 64.81 \pm 4.65$ vs. $99.16 \pm 9.60 \mathrm{ng} / \mathrm{mL}, \mathrm{P}<0.001$, Figure 3).

\section{Effect of RXM on expression of calprotectin in OVA + FCA-induced rats}

Calprotectin plays a critical role in the inflammatory response (26), so we examined its expression in BALF, serum, and lung tissue. Our results revealed a notable increase in the concentration of both BALF and serum calprotectin in the asthma group relative to the control group $(15.07 \pm 1.79$ vs. $3.86 \pm 0.69 \mathrm{ng} / \mathrm{mL} ; 20.47 \pm 1.64 v s$. $9.29 \pm 1.31 \mathrm{ng} / \mathrm{mL}$; all $\mathrm{P}<0.001$, Figure $3 C)$. Similar results were found according to the ELISA results for the lung tissue homogenates $(28.82 \pm 1.01$ vs. $12.02 \pm 1.38 \mathrm{ng} / \mathrm{mg}$, $\mathrm{P}<0.001$, Figure $4 A$ ). In contrast, RXM reversed the expression pattern of calprotectin compared with the asthma group $(11.21 \pm 0.76$ vs. $15.07 \pm 1.79 \mathrm{ng} / \mathrm{mL}, \mathrm{P}=0.001$; $14.36 \pm 0.78$ vs. $20.47 \pm 1.64 \mathrm{ng} / \mathrm{mL}, \mathrm{P}<0.001 ; 16.94 \pm 1.40$ vs. $28.82 \pm 1.01 \mathrm{ng} / \mathrm{mg}, \mathrm{P}<0.001$, Figures $3 C, 4 A$ ).

\section{Involvement of RAGE in the effect of RXM on OVA + FCA-induced changes in calprotectin expression}

As illustrated in Figure 4B,C, RAGE was upregulated after OVA + FCA exposure $(1.06 \pm 0.05$ vs. $0.18 \pm 0.05, \mathrm{P}<0.001)$. ELISA analysis also showed high levels of RAGE in BALF, serum, and lung tissue compared with controls $(762.93 \pm 36.47$ vs. $294.25 \pm 45.92 \mathrm{ng} / \mathrm{mL} ; 906.43 \pm 58.95$ vs. 
A

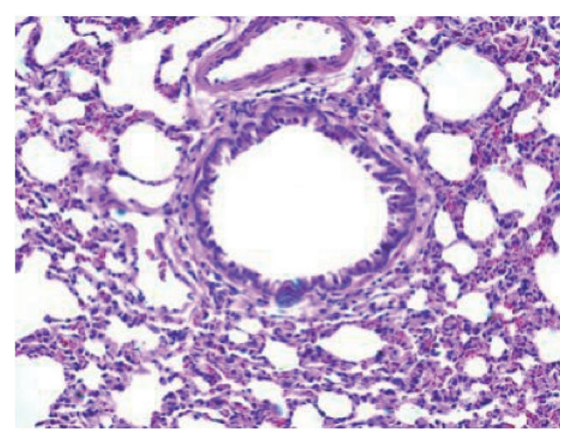

Asthma+RXM

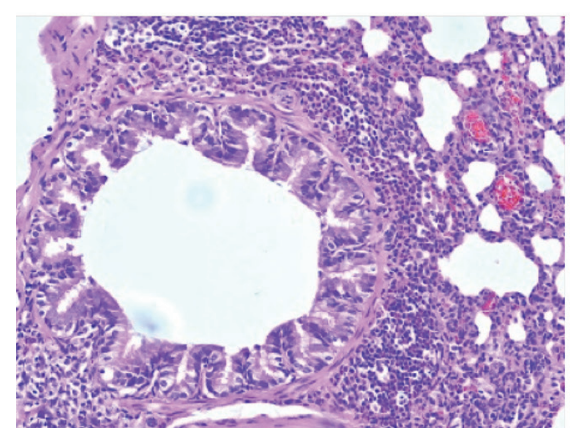

Asthma

Asthma+FPS-ZM1

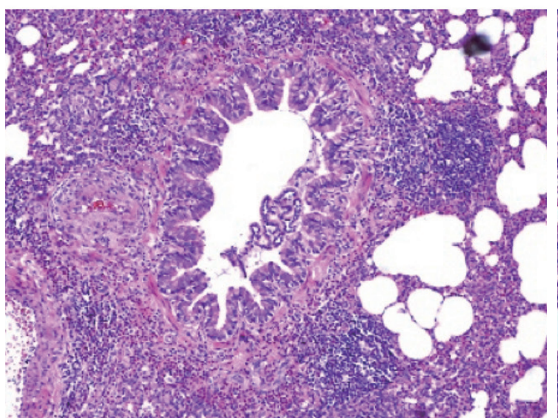

B

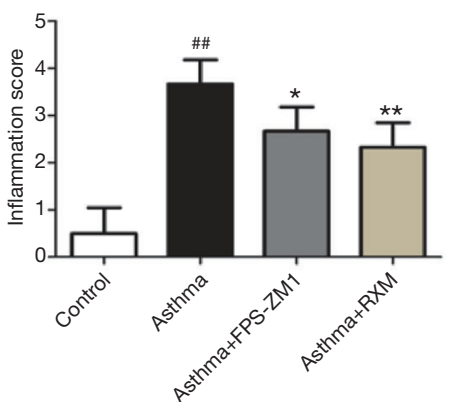

Figure 2 Effects of roxithromycin (RXM) on lung histopathology of ovalbumin (OVA)+ Freund's complete adjuvant (FCA)-induced rats. Hematoxylin and eosin (H\&E) staining of lung tissues at $200 \times$ magnification (A). The inflammation score of each group (B). The data are expressed as mean \pm standard deviation $(\mathrm{SD})\left(\mathrm{n}=4-6\right.$ per group). ${ }^{\#}, \mathrm{P}<0.01$ compared to the control group; * $\mathrm{P}<0.05$ compared to the asthma group; **, $\mathrm{P}<0.01$ compared to the asthma group.

$505.60 \pm 30.16 \mathrm{ng} / \mathrm{mL} ; 1,585.24 \pm 177.59$ vs. $461.53 \pm 63.40$ $\mathrm{ng} / \mathrm{mg}$; all $\mathrm{P}<0.001$, Figures $3 D, 4 D) ; \mathrm{RXM}$ treatment significantly inhibited this elevation $(559.70 \pm 64.32 \mathrm{vs}$. $762.93 \pm 36.47 \mathrm{ng} / \mathrm{mL} ; 649.85 \pm 61.33$ vs. $906.43 \pm 58.95$ $\mathrm{ng} / \mathrm{mL} ; 860.30 \pm 134.56$ vs. $1,585.24 \pm 177.59 \mathrm{ng} / \mathrm{mg}$; all $\mathrm{P}<0.001)$. To further investigate the mechanisms of RXM intervention in calprotectin expression and neutrophilic asthma, we used the FPS-ZM1 group for comparison. As expected, FPS-ZM1 suppressed calprotectin expression and reduced airway inflammation, further supporting a preeminent role for RAGE in the pathogenesis of neutrophilic asthma.

\section{Correlative analysis of various parameters}

The ELISA revealed that the concentration of calprotectin correlated positively to the concentration of RAGE $(\mathrm{r}=0.9611,0.9063,0.9353$; all $\mathrm{P}<0.001$; Figures $4 E, 5 A, B)$. The concentration of calprotectin correlated positively to IL-17 in both serum and BALF ( $r=0.8674$, 0.9670; all
$\mathrm{P}<0.001$; Figure $5 C, D)$, and it also correlated positively to IL-6 in both serum and BALF ( $\mathrm{r}=0.9037,0.9362$; all $\mathrm{P}<0.001$; Figure $5 E, F)$. Moreover, there was a positive correlation between calprotectin and both total BALF cells and total neutrophils ( $\mathrm{r}=0.9096,0.8760$; all $\mathrm{P}<0.001$; Figure $5 G, H)$.

\section{Discussion}

Neutrophils and their harmful secretions are well recognized as one of the reliable clinical biomarkers of lung disease progression (27). Pronounced airway neutrophil infiltration is a central feature of neutrophilic asthma, which is a major cause of both severe and refractory asthma $(1,2)$. Based on our earlier findings, we developed a neutrophilic asthma model induced by OVA and FCA. Our results revealed airway hyperresponsiveness and a notable increase in neutrophil-predominant inflammatory cells in the OVA + FCA-induced rats. Neutrophil infiltration is known to involve a vast array of chemokines and cytokines. IL-17 

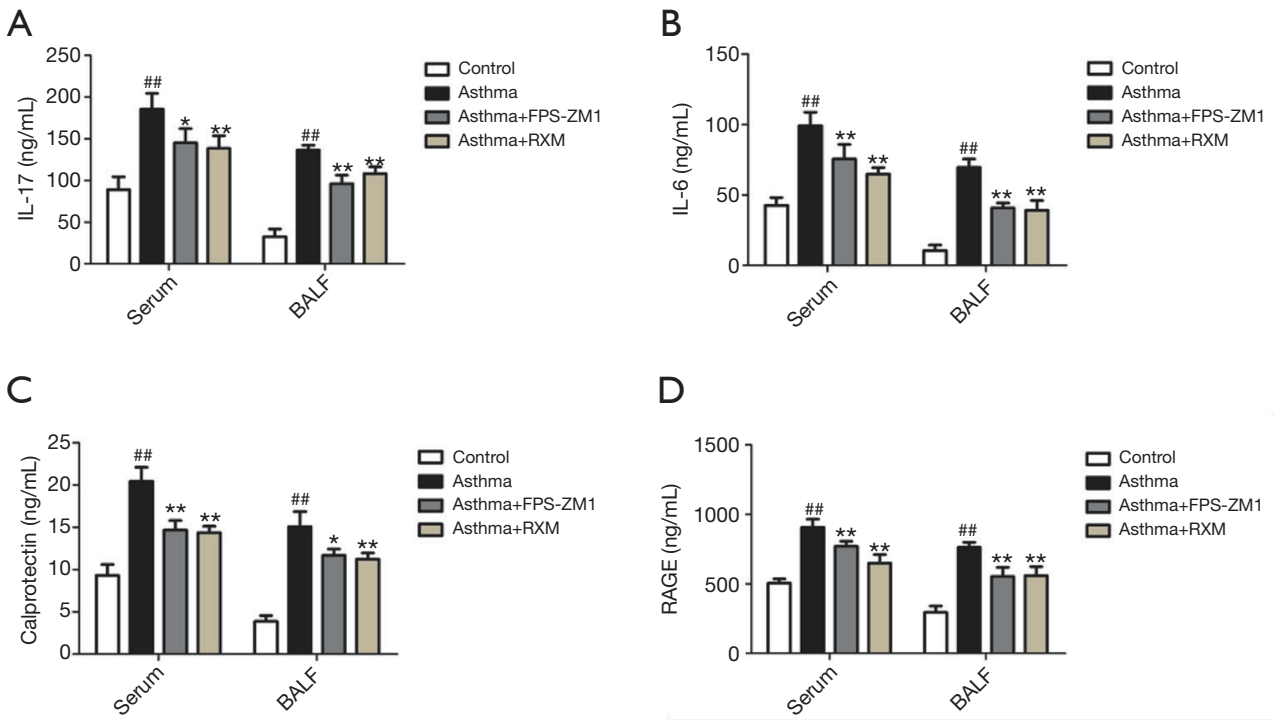

Figure 3 Effects of roxithromycin (RXM) on inflammatory cytokines, calprotectin and the receptor of advanced glycation end products (RAGE) in serum and bronchoalveolar lavage fluid (BALF). The concentrations of interleukin (IL)-17 (A), IL-6 (B), calprotectin (C), and RAGE (D) in serum and BALF by Enzyme-linked immunosorbent assay (ELISA). Results were obtained from three independent experiments. The data are expressed as mean \pm standard deviation (SD) ( $\mathrm{n}=4-6$ per group). ${ }^{\# \#}, \mathrm{P}<0.01$ compared to the control group; *, $\mathrm{P}<0.05$ compared to the asthma group; ${ }^{* *}, \mathrm{P}<0.01$ compared to the asthma group.

and IL-6, among other cytokines, are crucial mediators of neutrophil recruitment and activation $(28,29)$. Previous research has demonstrated that the airway tissues of asthmatic subjects with severe and persistent symptoms are characterized by preferential neutrophilic infiltration with elevated levels of both IL-17 and IL-6 (28-30). In addition to the increased airway neutrophils, our current study detected upregulation of IL-17 and IL-6 in both the serum and BALF from the asthmatic rats, which corroborated our model of neutrophil-mediated inflammation. Our primary finding was that pretreatment with RXM alleviated airway inflammation and modulated the expression of calprotectin and RAGE in neutrophilic asthmatic rats. Further, we found that blocking RAGE activation suppressed calprotectin expression and weakened the inflammatory response.

Calprotectin, as one of the DAMPs belonging to the family of $\mathrm{Ca}^{2+}$-binding proteins, has been identified as a critical component of inflammatory diseases, including asthma $(8,10)$. Differential proteomic analysis of BALF from asthmatic subjects has revealed that calprotectin is strongly linked to the pathogenesis of airway inflammation (31). The expression of calprotectin in lung tissue is significantly elevated during the early stage of OVA-induced asthma, so calprotectin may be involved in the initiation of the early inflammatory response in asthma (9). Moreover, proteomic identification of $\mathrm{MMP}_{-} 2^{-/} / \mathrm{MMP}-9^{-/-}$asthmatic mice demonstrated that calprotectin was upregulated and that function-blocking antibodies to calprotectin meaningfully inhibited the migration of inflammatory cells into the alveolar space. This finding indicates that calprotectin induces chemotaxis and migration of airway inflammatory cells in asthma (32).

Recent evidence has shown that calprotectin exerts its proinflammatory functions mainly by binding to the pattern recognition receptor (PRR) RAGE and thus activating inflammation-related downstream signaling pathways and upregulating the expression of proinflammatory cytokines (33). Another study showed that calprotectin could be upregulated with a high AGE burden, thereby aggravating proinflammatory conditions via the activation of RAGE; calprotectin expression and proinflammatory conditions were significantly suppressed by RAGE antagonism (34). In our previous experiment, we found that the concentration of S100A8 in asthmatic rats was notably increased, with relatively higher levels of RAGE (35). In this study, we added the FPS-ZM1 group, to further verify that the significant elevation of calprotectin in our neutrophilic asthma model positively correlated with the concentration of RAGE and airway inflammation. Most importantly, all of these 
A

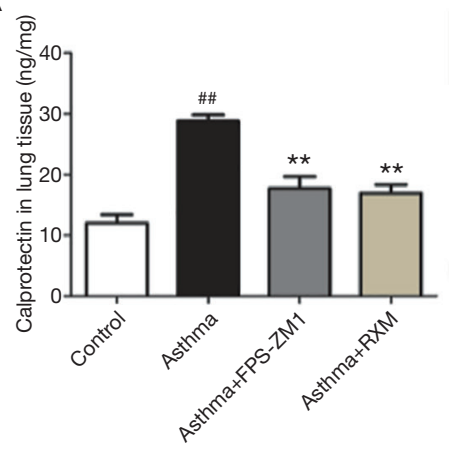

D

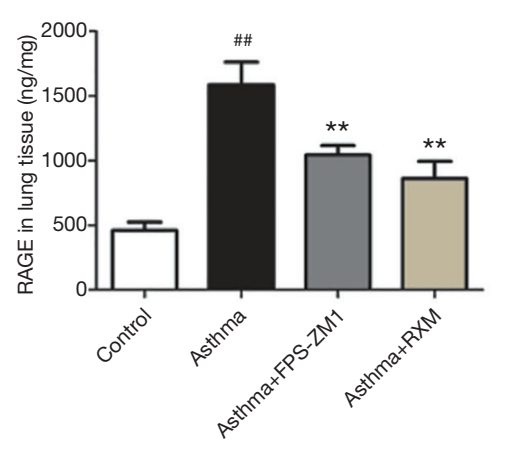

B

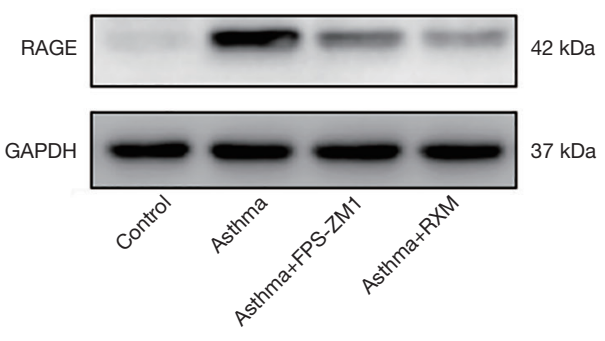

E

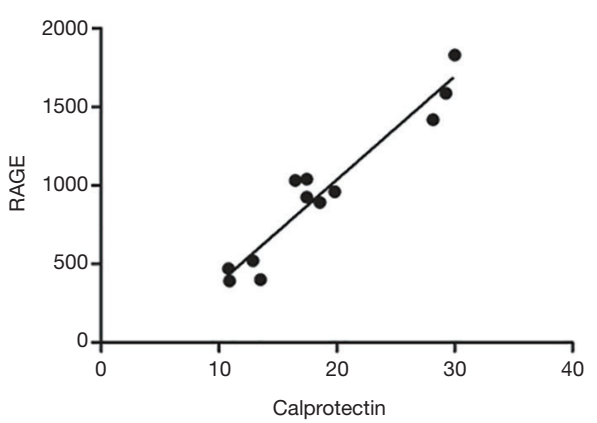

C

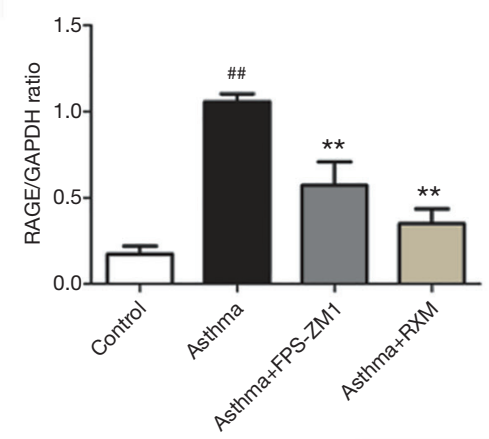

Figure 4 Effects of roxithromycin (RXM) on calprotectin and the receptor of advanced glycation end products (RAGE) in lung tissue. The concentration of lung tissue calprotectin (A) by Enzyme-linked immunosorbent assay (ELISA). The expression of RAGE in lung tissue was analyzed by Western blotting (B) and normalized to the levels of glyceraldehyde-3-phosphate dehydrogenase (GAPDH) (C). The concentration of lung tissue RAGE (D) by ELISA. The correlation between RAGE and calprotectin in lung tissue ( $\mathrm{r}=0.9611$; E). Results were obtained from three independent experiments. Data are expressed as mean \pm standard deviation (SD) ( $\mathrm{n}=4-6$ per group). ${ }^{\#}, \mathrm{P}<0.01$ compared to the control group; ${ }^{* *}, \mathrm{P}<0.01$ compared to the asthma group.

changes were alleviated by FPS-ZM1. These findings are in accordance with the results from the other studies discussed above.

As a PRR, RAGE has emerged as a key regulator of inflammatory processes (36), and it is strongly expressed in the lungs (12). Genome-wide association studies have identified RAGE as an important player in the pathogenesis of human asthma (37). Clinical studies have suggested an increased level of RAGE is present in sputum samples from asthmatic subjects; such levels correlate with disease severity (38). In a house dust mite asthmatic model, RAGE-knockout mice were devoid of most of the pathological features, including airway hypersensitivity, airway inflammation, and airway remodeling, that are found in wild-type mice. Furthermore, these findings were reproduced in an OVA-induced asthmatic model, which demonstrated the fundamental importance of RAGE in asthma (39). Additional analysis revealed that RAGE promoted IL-33 expression and mediated its downstream inflammatory signaling effects in response to asthma; the absence of RAGE impeded this reaction (40). In the present study, OVA + FCA-induced rats showed elevated RAGE expression levels, and RAGE inhibition attenuated OVA + FCA-induced airway inflammation, which confirms the pronounced significance of RAGE in neutrophilic asthma.

Given the inefficacy of corticosteroids in neutrophilic asthma, considerable interest has been given to potential alternative therapeutics. Because infections with bacteria and viruses are moderately associated with asthma severity (41), antibiotics, especially macrolides, have shown promise, as presented in decreased sputum neutrophil counts and alleviation of symptoms (42-44). Our previous study found 

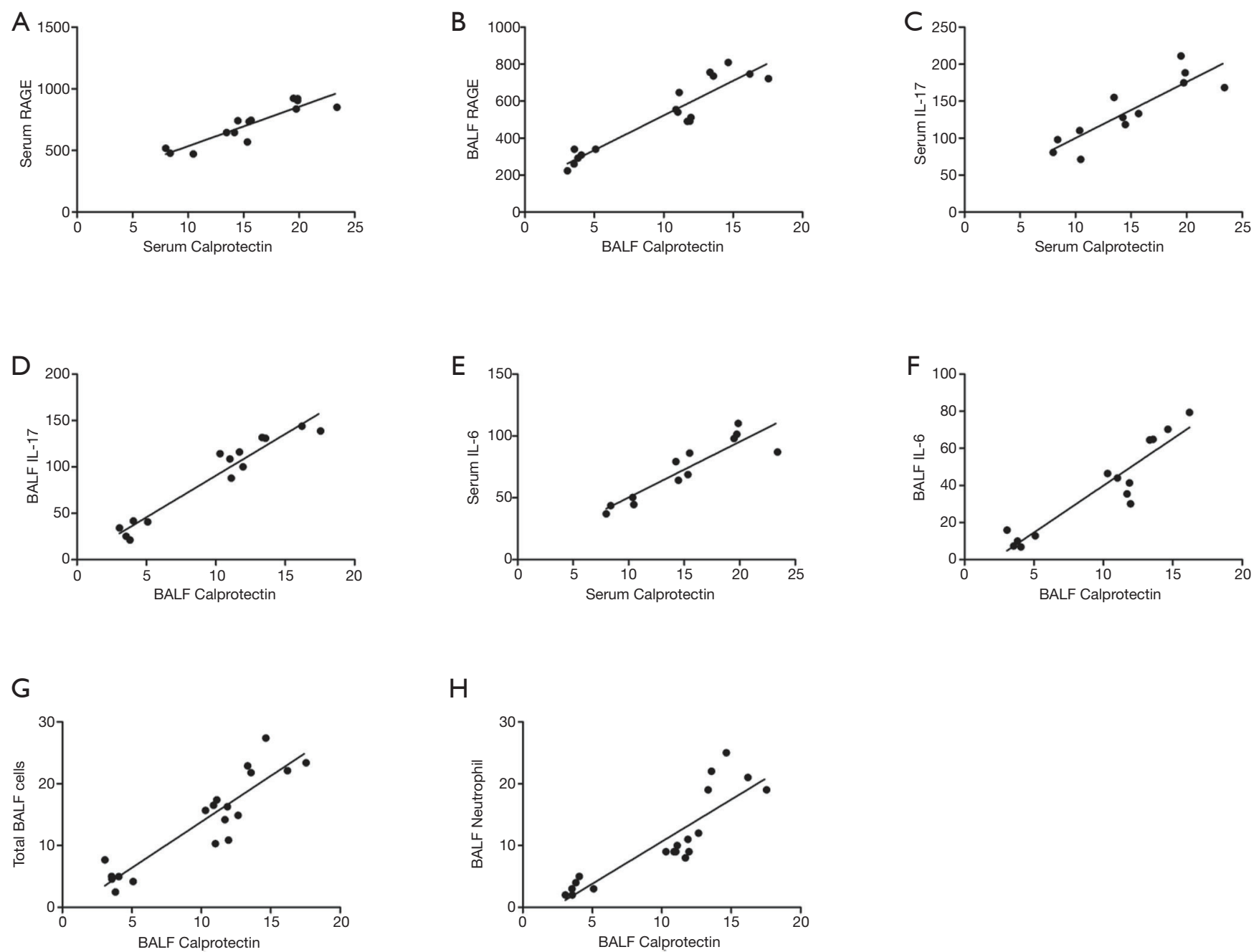

Figure 5 The correlation among different parameters. The correlation between the receptor of advanced glycation end products (RAGE) and calprotectin in serum ( $\mathrm{r}=0.9063, \mathrm{~A})$ and bronchoalveolar lavage fluid (BALF) $(\mathrm{r}=0.9353, \mathrm{~B})$. The correlation between interleukin (IL)-17 and calprotectin in serum $(r=0.8674, \mathrm{C})$ and BALF $(r=0.9670, \mathrm{D})$. The correlation between IL-6 and calprotectin in serum ( $\mathrm{r}=0.9037$, E) and BALF ( $r=0.9362, F)$. The correlation between total inflammatory cells and calprotectin in BALF ( $r=0.9096$, G). The correlation between neutrophils and calprotectin in BALF ( $\mathrm{r}=0.8760, \mathrm{H})$. $\mathrm{n}=4-6$ per group, all $\mathrm{P}<0.01$.

that RXM could reduce airway inflammation by inhibiting the PI3K-ס/Akt signaling pathway and upregulating histone deacetylase 2 (HDAC2) expression (22). In the present study, RXM treatment reduced the number of airway inflammatory cells, neutrophils, and the concentration of inflammatory cytokines. RXM was also associated with downregulation of calprotectin and RAGE.

In conclusion, pretreatment with RXM exerted similar effects as the RAGE inhibitor FPS-ZM1, and RXM may suppress calprotectin expression via inhibition of RAGE activation, further suppressing the secretion of inflammatory cytokines and airway inflammation, which improves the neutrophilic asthma. Our findings provide novel insights into the mechanism of RXM in neutrophilic asthma; namely, that a RAGE inhibitor may be a potential candidate for neutrophilic asthma therapy. Additional studies are underway that are exploring the promising new therapeutic options for neutrophilic asthma of inhibiting calprotectin and RAGE.

\section{Acknowledgments}

Funding: This work was supported by the National Natural 
Science Foundation of China (81570027); Zhejiang Natural Science Funding (LY16H010007); Jinhua Science and Technology Bureau (2017-3-010).

\section{Footnote}

Reporting Checklist: The authors have completed the ARRIVE reporting checklist. Available at http://dx.doi. org/10.21037/atm-21-859

Data Sharing Statement: Available at http://dx.doi. org/10.21037/atm-21-859

Conflicts of Interest: All authors have completed the ICMJE uniform disclosure form (available at http://dx.doi. org/10.21037/atm-21-859). The authors have no conflicts of interest to declare.

Ethical Statement: The authors are accountable for all aspects of the work in ensuring that questions related to the accuracy or integrity of any part of the work are appropriately investigated and resolved. Experiments were performed under a project license (protocol wydw2019-019) granted by the Animal Care and Protection Committee of Wenzhou Medical University, in compliance with the Animal Care and Protection Committee of Wenzhou Medical University guidelines for the care and use of animals.

Open Access Statement: This is an Open Access article distributed in accordance with the Creative Commons Attribution-NonCommercial-NoDerivs 4.0 International License (CC BY-NC-ND 4.0), which permits the noncommercial replication and distribution of the article with the strict proviso that no changes or edits are made and the original work is properly cited (including links to both the formal publication through the relevant DOI and the license). See: https://creativecommons.org/licenses/by-nc-nd/4.0/.

\section{References}

1. Ravi A, Chowdhury S, Dijkhuis A, et al. Neutrophilic inflammation in asthma and defectiveepithelial translational control. Eur Respir J 2019;54:1900547.

2. Ray A, Kolls JK. Neutrophilic inflammation in asthma and association with disease severity. Trends Immunol 2017;38:942-54.

3. Averill MM, Kerkhoff C, Bornfeldt KE. S100A8 and
S100A9 in cardiovascular biology and disease. Arterioscler Thromb Vasc Biol 2012;32:223-9.

4. Chen B, Miller AL, Rebelatto M, et al. S100A9 induced inflammatory responses are mediated by distinct damage associated molecular patterns (DAMP) receptors in vitro and in vivo. PLoS ONe 2015;10:e0115828.

5. Ehrchen JM, Sunderkötter C, Foell D, et al. The endogenous Toll-like receptor 4 agonist S100A8/ S100A9 (calprotectin) as innate amplifier of infection, autoimmunity, and cancer. J Leukoc Biol 2009;86:557-66.

6. Gebhardt C, Németh J, Angel P, et al. S100A8 and S100A9 in inflammation and cancer. Biochem Pharmacol 2006;72:1622-31.

7. Lee YG, Hong J, Lee PH, et al. Serum Calprotectin Is a Potential Marker in Patients with Asthma. J Korean Med Sci 2020;35:e362.

8. Goyette J, Geczy CL. Inflammation-associated S100 proteins: new mechanisms that regulate function. Amino Acids 2011;41:821-42.

9. Otsuka K, Terasaki F, Ikemoto M, et al. Suppression of inflammation in rat autoimmune myocarditis by S100A8/ A9 through modulation of the proinflammatory cytokine network. Eur J Heart Fail 2009;11:229-37.

10. Halayko AJ, Ghavami S. S100A8/A9: a mediator of severe asthma pathogenesis and morbidity? Can J Physiol Pharmacol 2009;87:743-55.

11. Xu YD, Cui JM, Wang Y, et al. The early asthmatic response is associated with glycolysis, calcium binding and mitochondria activity as revealed by proteomic analysis in rats. Respir Res 2010;11:107.

12. Hudson BI, Lippman ME. Targeting RAGE Signaling in Inflammatory Disease. Annu Rev Med 2018;69:349-64.

13. Turovskaya O, Foell D, Sinha P, et al. RAGE, carboxylated glycans and S100A8/A9 play essential roles in colitisassociated carcinogenesis. Carcinogenesis 2008;29:2035-43.

14. Gebhardt C, Riehl A, Durchdewald M, et al. RAGE signaling sustains inflammation and promotes tumor development. J Exp Med 2008;205:275-85.

15. Hofmann MA, Drury S, Hudson BI, et al. RAGE and arthritis: the G82S polymorphism amplifies the inflammatory response. Genes Immun 2002;3:123-35.

16. Suzuki J, Ogawa M, Hishikari K, et al. Novel effects of macrolide antibiotics on cardiovascular diseases. Cardiovasc Ther 2012;30:301-7.

17. Berman M, Hasdai D, Raanani E, et al. Ex-vivo effect of roxithromycin on human and rat arterial vasoactivity. Interact Cardiovasc Thorac Surg 2005;4:232-7. 


\section{Page 10 of 11}

18. Kalea AZ, Schmidt AM, Hudson BI. RAGE: a novel biological and genetic marker for vascular disease. Clin Sci (Lond) 2009;116:621-37.

19. Kumar VL, Pandey A, Ahmad H. Effect of roxithromycin on contractile activity of gastrointestinal smooth muscles in colitic rats. J Basic Clin Physiol Pharmacol 2021. [Epub ahead of print]. doi: 10.1515/jbcpp-2020-0051.

20. Ahmad H, Verma S, Kumar VL. Effect of roxithromycin on mucosal damage, oxidative stress and pro-inflammatory markers in experimental model of colitis. Inflamm Res 2018 Feb;67:147-55.

21. Choe HS, Lee SJ, Han CH, et al. Clinical efficacy of roxithromycin in men with chronic prostatitis/chronic pelvic pain syndrome in comparison with ciprofloxacin and aceclofenac: a prospective, randomized, multicenter pilot trial. J Infect Chemother 2014;20:20-5.

22. Xia M, Xu H, Dai W, et al. The role of HDAC2 in cigarette smoke-induced airway inflammation in a murine model of asthma and the effect of intervention with roxithromycin. J Asthma 2018;55:337-44.

23. Wu LQ, Wang RL, Dai YR, et al. Roxithromycin suppresses airway remodeling and modulates the expression of caveolin-1 and phospho-p42/p44MAPK in asthmatic rats. Int Immunopharmacol 2015;24:247-55.

24. Dejager L, Dendoncker K, Eggermont M, et al. Neutralizing TNF $\alpha$ restores glucocorticoid sensitivity in a mouse model of neutrophilic airway inflammation. Mucosal Immunol 2015;8:1212-25.

25. Zeng Z, Lin X, Zheng R, et al. Celastrol Alleviates Airway Hyperresponsiveness and Inhibits Th17 Responses in Obese Asthmatic Mice. Front Pharmacol 2018;9:49.

26. Sunahori K, Yamamura M, Yamana J, et al. The S100A8/ A9 heterodimer amplifies proinflammatory cytokine production by macrophages via activation of nuclear factor kappa B and p38 mitogen-activated protein kinase in rheumatoid arthritis. Arthritis Res Ther 2006;8:R69.

27. Laucirica DR, Garratt LW, Kicic A. Progress in Model Systems of Cystic Fibrosis Mucosal Inflammation to Understand Aberrant Neutrophil Activity. Front Immunol 2020;11:595.

28. Yang X, Jiang Y, Wang C. Does IL-17 Respond to the Disordered Lung Microbiome and Contribute to the Neutrophilic Phenotype in Asthma? Mediators Inflamm 2016;2016:6470364.

29. Mateer SW, Mathe A, Bruce J, et al. Interleukin-6 drives neutrophil-mediated pulmonary inflammation associated with bacteraemia in murine models of colitis. Am J Pathol 2018;188:1625-39.

\section{Gu et al. Roxithromycin alleviates asthmatic airway inflammation}

30. Wang YH, Wills-Karp M. The potential role of interleukin-17 in severe asthma. Curr Allergy Asthma Rep 2011;11:388-94.

31. Wu J, Kobayashi M, Sousa EA, et al. Differential proteomic analysis of bronchoalveolar lavage fluid in asthmatics following segmental antigen challenge. Mol Cell Proteomics 2005;4:1251-64.

32. Greenlee KJ, Corry DB, Engler DA, et al. Proteomic Identification of In Vivo Substrates for Matrix Metalloproteinases 2 and 9 Reveals a Mechanism for Resolution of Inflammation. J Immunol 2006;177:7312-21.

33. Narumi K, Miyakawa R, Ueda R, et al. Proinflammatory Proteins S100A8/S100A9 Activate NK Cells via Interaction with RAGE. J Immunol 2015;194:5539-48.

34. Eggers K, Sikora K, Lorenz M, et al. RAGE-Dependent Regulation of Calcium-Binding Proteins S100A8 and S100A9 in Human THP-1. Exp Clin Endocrinol Diabetes 2011;119:353-7.

35. Gu XF, Chen XM, Chen HJ, et al. The role of S100A8/ RAGE and Caveolin-1 and the effect of roxithromycin on their expression in a rat model of neutrophilic asthma. Zhonghua Jie He He Hu Xi Za Zhi 2019;42:845-51.

36. Salminen A, Ojala J, Kauppinen A, et al. Inflammation in Alzheimer's disease: Amyloid- $\beta$ oligomers trigger innate immunity defence via pattern recognition receptors. Prog Neurobiol 2009;87:181-94.

37. Hancock DB, Eijgelsheim M, Wilk JB, et al. Meta-analyses of genome-wide association studies identify multiple loci associated with pulmonary function. Nat Genet 2010;42:45-52.

38. Bediwy AS, Hassan SM, El-Najjar MR. Receptor of advanced glycation end products in childhood asthma exacerbation. Egypt J Chest Dis Tuberc 2016;65:15-8.

39. Milutinovic PS, Alcorn JF, Englert JM, et al. The Receptor for Advanced Glycation End Products Is a Central Mediator of Asthma Pathogenesis. Am J Pathol 2012;181:1215-25.

40. Oczypok EA, Milutinovic PS, Alcorn JF, et al. Pulmonary receptor for advanced glycation end-products promotes asthma pathogenesis through IL-33 and accumulation of group 2 innate lymphoid cells. J Allergy Clin Immunol 2015;136:747-756.e4.

41. Ray A, Raundhal M, Oriss TB, et al. Current concepts of severe asthma. J Clin Invest 2016;126:2394-403.

42. Kew KM, Undela K, Kotortsi I, et al. Macrolides for chronic asthma. Cochrane Database Syst Rev 2015;(9):CD002997. 
43. Simpson JL, Powell H, Boyle MJ, et al. Clarithromycin targets neutrophilic airway inflammation in refractory asthma. Am J Respir Crit Care Med 2008;177:148-55.

44. Slater M, Rivett DW, Williams L, et al. The impact of

Cite this article as: Gu X, Shu D, Ying S, Dai Y, Zhang Q, Chen X, Chen H, Dai W. Roxithromycin attenuates inflammation via modulation of RAGE-influenced calprotectin expression in a neutrophilic asthma model. Ann Transl Med 2021;9(6):494. doi: 10.21037/atm-21-859 azithromycin therapy on the airway microbiota in asthma. Thorax 2014;69:673-4.

(English Language Editor: K. Brown) 